\title{
German monitoring 2012-2014: ergot of Claviceps purpurea and ergot alkaloids (EA) in feedingstuffs and their toxicological relevance for animal feeding
}

\author{
Christine Schwake-Anduschus ${ }^{1} \cdot$ Nicole Lorenz $^{2} \cdot$ Monika Lahrssen-Wiederholt $^{2} \cdot$ Anke Lauche $^{3}$ (i) $\cdot$ Sven Dänicke ${ }^{4}$ (D)
}

Received: 26 May 2020 / Revised: 1 September 2020 / Accepted: 8 September 2020 / Published online: 22 October 2020

(c) The Author(s) 2020

\begin{abstract}
Feedingstuffs are frequently contaminated with sclerotia (ergot) of the phytopathogenic fungus Claviceps purpurea. Ergot contains ergot alkaloids (EA), but the amount and composition of these substances may be highly variable hampering the extrapolation of the amount of EA from the ergot content. 600 different feed samples from the harvest years 2011-2014 (rye, triticale, wheat, mixed cereal grains or compound feed), preferably those with visible ergot infestation, were analyzed for both parameters ergot and EA content in a German monitoring program. The analytical results were employed for statistical evaluation using the software $\mathrm{JMP}^{\circledR} 13$. The data show that the correlation between the ergot and the EA content was rather poor, especially for rye, the grain most frequently contaminated with ergot and EA. Consequently, effects on animal health correlated much better with EA than with ergot content. Furthermore, it shows that the current European law for undesirable substances (Directive 2002/32/EC) restricting the ergot content in feed materials and compound feed containing unground cereals is not fully sufficient to protect animal health. Therefore, preliminary guidance values for species-specific critical values for total EA content in the diets are derived and suggested for practical use. Further research is needed to verify these preliminary guidance values and to improve risk evaluation in consideration of the significant variability in the speciesspecific sensitivity.
\end{abstract}

Keywords Animal feeding $\cdot$ Animal health $\cdot$ Claviceps purpurea $\cdot$ Ergot alkaloids $\cdot$ Rye $\cdot$ Ergot

\section{Introduction}

The term "ergot" (sclerotia) refers to the compact mass of fungal mycelia from Claviceps spp. Ergot may form on grain ears of infested cereal plants and thereby replace healthy kernels. Normally, ergot is coloured blackish-brown, partly reflecting a purple shimmer. Apart from amines, amino

Anke Lauche

anke.lauche@bvl.bund.de

1 Department of Safety and Quality of Cereals, Max RubnerInstitut (MRI), Federal Research Institue of Nutrition and Feed, 32756 Detmold, Germany

2 Department Safety in the Food Chain, German Federal Institute for Risk Assessment (BfR), 10589 Berlin, Germany

3 Unit "Feed", Federal Office of Consumer Protection and Food Safety (BVL), 10117 Berlin, Germany

4 Institute of Animal Nutrition, Friedrich-Loeffler-Institut (FLI), Federal Research Institute for Animal Health, 38116 Braunschweig, Germany acids, enzymes, oils, sterols and other substances, ergot contains up to 40 different ergot alkaloids (EA). These EA are chemically amide or peptide derivatives of lysergic acid. Based on the toxic properties of EA and other ergot compounds, the ingestion of contaminated food or feed may cause undesirable effects in humans or in animals [summarized e.g. in EFSA $(2005 ; 2012)]$.

In principle, ergot may occur in a wide variety of grasses and cereals. In Germany, however, rye and triticale are the most frequently infected cereals. Ergot is harvested along with the cereal grains and thus contaminates the cereals intended for animal or human consumption. Development and distribution of ergot may vary between years (Sciurba et al. 2017) due to different climate conditions, but can be minimized by good agricultural and manufacturing practice (BMEL 2014).

Within the European Union (EU), the Directive 2002/32/ EC sets a maximum level (ML) of $1000 \mathrm{mg}$ rye ergot $/ \mathrm{kg}$ feed materials and compound feed containing unground cereals with a moisture content of $12 \%$. As ergot may vary 
considerably not only in size, weight and composition but also in the EA content (EFSA 2005; 2012), the European Commission recommended an EU-wide monitoring of the presence of EA in feed and food (Recommendation 2012/154/EU). The member states followed that, and in 2012, the Federal States of Germany agreed to initiate a national monitoring on EA.

One aim of the present study was to evaluate German monitoring data of the years 2012-2014 on preferably visible ergot infested cereal grains. For this purpose, the content of ergot was determined by the physical method while EA was analyzed chemically. The objective was to evaluate the general contamination level and to scrutinize possible correlations between ergot and EA. Six predominantly present EA, i.e. ergocornine, ergocristine, ergocryptine, ergometrine, ergosine and ergotamine and their related -inines forms, were considered as total EA and used for the evaluation of toxic effects in farm animals. Based on the conclusion of the Panel on Contaminants of the European Food Safety Authority (EFSA) that data on the sensitivity of farm animals to EA are incomplete and do not allow the establishment of tolerance levels for individual EA and mixtures thereof (EFSA 2005; 2012), a toxicological evaluation of EA content of complete diets is urgently necessary to protect animal health.

Hence, a second aim of the study was to derive preliminary guidance values for critical dietary EA concentrations based on recent literature and to use the German monitoring data for a risk evaluation.

\section{Materials and methods}

\subsection{Monitoring and statistical evaluation of parallel contamination of cereal grains with ergot and with EA}

In close collaboration with the competent authorities of its Federal States, Germany established a national monitoring program for the years 2012, 2013, and 2014. It was agreed that the monitoring should focus on sampling and analysis of unground rye and possibly triticale with preferably visible ergot infestation. The sampling was consequently not representative but more risk-oriented. Both ergot content and occurrence of analytically detectable EA (ergocornine, ergocristine, ergocryptine, ergometrine, ergosine, and ergotamine) as well as their epimers should be analyzed.

Furthermore, the competent authorities of the Federal States of Germany agreed on a certain procedure regarding the preparation for the laboratory analyses of the final sample. For analytical purposes, the final feed sample of $500 \mathrm{~g}$ was homogenized and divided into two portions of $250 \mathrm{~g}$ each. One of these portions was used for the microscopic analysis of the ergots. The whole fraction resulting from the microscopic analysis was then homogenized, crushed to particle sizes $\leq 0.5 \mathrm{~mm}$ and afterwards homogenized again. After this preparation, an aliquot of $20 \mathrm{~g}$ was analyzed for the content of EA. The concentration of EA was preferably examined by high-performance liquid chromatography fluorescence detection (HPLC), as described in method F 0104 according to $\S 64(2)$ of the German Food and Feed Code (BVL; Amtliche Sammlung von Untersuchungsverfahren nach § 64(2) LFGB 2012) BVL (Bundesamt für Verbraucherschutz und Lebensmittelsicherheit) (2010). 46 samples were analyzed via LC-MS/ MS method. Depending on the laboratory accuracy and the analytical matrices the limit of quantification (LOQ) for EA and its related -inine forms ranged from 1 to $20 \mu \mathrm{g} / \mathrm{kg}$.

The analytical results concerning the amount of ergot and of individual EA were reported to the Federal Office of Consumer Protection and Food Safety (BVL) and used for statistical evaluation. EA were expressed as sum of EA and its related -inine forms. Data below the limit of quantification were calculated as zero (lower bound). Statistical evaluation was performed using the software $\mathrm{JMP}^{\circledR}$ 13. Different types of statistical analyses were used for data interpretation, e.g., descriptive statistics, bi- and multivariate regressions, estimation of Pearson correlation coefficient, pairwise comparisons and others.

\subsection{Toxicity evaluation, derivation of preliminary guidance values for critical diet concentrations and risk evaluation}

In 2012, the EFSA released an opinion on EA as undesirable contaminants in feed and food. Since then a number of studies have been published dealing with toxic effects on animals hitherto not examined comprehensively including pigs, poultry and ruminant species. Most of these studies were performed according to the dose-response principle allowing derivation of lowest observed effect levels (LOAEL) and/or no-observed adverse effect levels (NOAEL). Other studies reported critical diet levels defined by authors themselves and concluded from their results. Although the current database has to be considered still as incomplete preliminary guidance values for critical diet concentrations of total EA were proposed.

In a second step, these guidance values served as the base for a risk evaluation by using the German monitoring data on the occurrence of the analyzed EA. 


\section{Results and discussion}

\subsection{Monitoring and statistical evaluation of parallel contamination of cereal grains with ergot and with $E A$}

In the context of the monitoring programs from 2012 to 2014, the competent authorities of the Federal States of Germany analyzed 600 feed samples, especially whole grain cereals including rye $(n=321)$, triticale $(n=197)$, wheat $(n=52)$, as well as mixed cereal grains and compound feed $(n=30)$. Whereas most of those samples were derived from whole grain cereals with visible ergot infestation $(\mathrm{n}=451)$, data analysis also included 149 samples from cereals without apparent ergot infestation. The cereal samples of the three monitoring years were harvested from 2011 to 2014.

Ergots and EA (above LOQ) were not detected in 13\% $(n=78)$ of investigated samples. The proportion of samples exceeding the maximum limit (ML) of $1000 \mathrm{mg}$ ergot per $\mathrm{kg}$ feed was close to $16 \%$. It should be noted that in some samples the levels of ergot and EA were both high e.g. $10,307 \mathrm{mg}$ ergot $/ \mathrm{kg}$ and $14,474 \mu \mathrm{g} \mathrm{EA} / \mathrm{kg}$, while in some patterns the levels of EA were high but the ergot content was comparatively low (e.g. 19,441 $\mu \mathrm{g} \mathrm{EA} / \mathrm{kg}$ and $624 \mathrm{mg} \mathrm{ergot} / \mathrm{kg}$ ), or vice versa (e.g. $847 \mu \mathrm{g} \mathrm{EA} / \mathrm{kg}$ and $2059 \mathrm{mg}$ ergot $/ \mathrm{kg})$.

$11.7 \%(\mathrm{n}=70)$ of the analyzed samples did not contain any ergot at the same time containing considerable levels of EA: a median of $33 \mu \mathrm{g} / \mathrm{kg}$, a mean of $137 \mu \mathrm{g} / \mathrm{kg}$, a $90 \mathrm{th}$ percentile of $321 \mu \mathrm{g} / \mathrm{kg}$ and a maximum content of total $1305 \mu \mathrm{g}$ of total EA $/ \mathrm{kg}$ feed.

In $9 \%(n=54)$ of the analyzed samples no EA were found although the ergot content showed a median of $183 \mathrm{mg} / \mathrm{kg}$, a mean of $285 \mathrm{mg} / \mathrm{kg}$, a 90th percentile of $640 \mathrm{mg} / \mathrm{kg}$ and a maximum content of $1829 \mathrm{mg}$ ergot $/ \mathrm{kg}$ feed.

Overall, in 2013 the levels of ergot and EA content in the studied samples were higher than the occurrence in the feed samples from the harvest years 2011, 2012 and 2014 (Table 1).

An extensive data cloud appears when the ergot content is plotted logarithmically against the EA content (Fig. 1). It is evident that the variation of the EA content is high regarding a given ergot content: at a given ergot content of about $1000 \mathrm{mg} / \mathrm{kg}$, the sum of EA contents ranges from about $10 \mu \mathrm{g} / \mathrm{kg}$ up to more than $20,000 \mu \mathrm{g} / \mathrm{kg}$ EA.

The first set (set 1) of analysis investigated all samples, whereas set 2 concentrated on samples with ergot content less than the existing ML for feed of $1000 \mathrm{mg} / \mathrm{kg}$. The later correlation procedure using set 2 was chosen to avoid that the small number of highly contaminated samples had an unintentionally great influence on the calculation of correlation. In addition, the samples above the ML should be rejected in practice and are therefore of minor interest when looking at the calculation of correlation between the EA content and the ergot content of one sample for monitoring purposes.

Over the whole number of analyzed samples $(n=600)$, a correlation coefficient of 0.6796 was estimated using the statistical evaluation software JMP ${ }^{\circledR} 13$ (procedure: correlations multivariate). The exclusion of those samples above the ML of $1000 \mathrm{mg}$ ergot per kg decreased the correlation coefficient to 0.3485 (Table 2).

Calculating correlations considering different years and grain types led to the minimum coefficient 0.2250 of set 2 (min to ML) in the year 2011 and the maximum coefficient 0.9746 of set 1 (min-max) in wheat. The second-best correlation between the ergot and the EA content appeared in the grain group "others" with 0.9359 (set 1 and set 2, respectively). By contrast, the poorest correlation between the EA content and ergot content was found in rye of set 2 (min to ML) (Table 2).

Interestingly, the majority of calculated correlation coefficients were below 0.7 ; the value that in the authors' view differentiates poor from acceptable correlations. Only in the years 2012 and 2013, in triticale, wheat and others higher correlation coefficients could be determined with the data set 1 . However, these higher correlation coefficients must be interpreted with caution due to a small amount of extraordinary highly contaminated samples, which might be responsible for shaping the linear relationship. The values of correlation coefficients calculated with set 2 are all smaller than 0.7 (except for the limited number of grain type "others") and thus confirming the before mentioned "shaping-factor".

Our findings regarding the poor correlation of ergot and EA content contrast with the findings published by EFSA (2017). Therein data of two providers (638 samples) were analyzed and a linear relationship was observed between the ergot content and the levels of EA analyzed with higher Pearson correlation coefficients ranging between 0.806 for rye and 0.972 for triticale (EFSA 2017). To the best of our knowledge, the EFSA statement is based on the calculated Pearson correlation coefficient (PCC) of the whole data set. The present study shows that the PCC decreased strongly by excluding the few samples above the ML from statistical analysis (Table 2). Thus, a few highly contaminated samples might be responsible for shaping the linear relationship extraordinarily and thus encourage a misleading interpretation of the relationship between ergot content and analyzed EA in other studies. However, it has to be emphasized that the samples of the study at hand were collected solely in 
Germany. Nevertheless, the authors agree that correlations between the EA and the ergot content are less characteristic in the given sample sets. However, especially in rye, the grain with the highest risk of infection, the lowest correlation was observed.

Table 1 Summary: results of the study of German feed samples from the harvest years 2011-2014 on ergot and ergot alkaloids (EA)

\begin{tabular}{|c|c|c|c|c|c|c|c|c|}
\hline Statistical parameter & $\begin{array}{l}\text { Ergo-cornine } \\
\text { Content } \\
{[\mu \mathrm{g} / \mathrm{kg}]}\end{array}$ & Ergo-cristine & Ergo-cryptine & Ergo-metrine & Ergo-sine & Ergo-tamine & Sum of EAs & $\begin{array}{l}\text { Ergot } \\
\text { Content }[\mathrm{mg} / \mathrm{kg}]\end{array}$ \\
\hline LOQ $[\mu \mathrm{g} / \mathrm{kg}]$ & $1-20$ & $1-20$ & $1-20$ & $1-20$ & $1-20$ & $1-20$ & & \\
\hline \multicolumn{9}{|c|}{ Years 2011 to $2014(n=600)$} \\
\hline Median & 0 & 0 & 0 & 12 & 0 & 12 & 86 & 162 \\
\hline 70th perc. & 35 & 42 & 32 & 34 & 54 & 68 & 402 & 478 \\
\hline 80th perc. & 78 & 118 & 68 & 53 & 111 & 145 & 728 & 788 \\
\hline 90th perc. & 288 & 354 & 207 & 106 & 278 & 381 & 1759 & 1661 \\
\hline Mean & 134 & 231 & 159 & 90 & 124 & 223 & 961 & 620 \\
\hline SD & 591 & 1067 & 1253 & 479 & 445 & 965 & 4065 & 1412 \\
\hline Max & 10,114 & 15,743 & 20,826 & 6511 & 6654 & 14,502 & 61,951 & 14,798 \\
\hline \multicolumn{9}{|l|}{ Year $2011(\mathrm{n}=17)$} \\
\hline Median & 0 & 0 & 0 & 0 & 0 & 0 & 46 & 65 \\
\hline 70th perc. & 31 & 3 & 25 & 12 & 25 & 16 & 94 & 208 \\
\hline 80th perc. & 37 & 17 & 33 & 15 & 64 & 20 & 316 & 227 \\
\hline 90th perc. & 135 & 107 & 142 & 18 & 81 & 232 & 819 & 975 \\
\hline Mean & 37 & 31 & 38 & 8 & 34 & 65 & 214 & 262 \\
\hline SD & 69 & 75 & 73 & 12 & 65 & 152 & 360 & 455 \\
\hline Max & 242 & 245 & 233 & 43 & 258 & 572 & 1081 & 1406 \\
\hline \multicolumn{9}{|l|}{ Year $2012(n=198)$} \\
\hline Median & 0 & 0 & 0 & 13 & 0 & 0 & 79 & 161 \\
\hline 70th perc. & 26 & 45 & 30 & 36 & 43 & 38 & 305 & 357 \\
\hline 80th perc. & 58 & 91 & 49 & 53 & 70 & 115 & 573 & 623 \\
\hline 90th perc. & 225 & 291 & 129 & 83 & 159 & 264 & 1181 & 1762 \\
\hline Mean & 71 & 134 & 43 & 38 & 82 & 114 & 482 & 519 \\
\hline SD & 184 & 431 & 98 & 91 & 256 & 328 & 1203 & 998 \\
\hline Max & 1533 & 4170 & 644 & 1002 & 2565 & 2437 & 10,289 & 7157 \\
\hline \multicolumn{9}{|l|}{ Year $2013(n=273)$} \\
\hline Median & 0 & 5 & 0 & 17 & 19 & 24 & 162 & 264 \\
\hline 70th perc. & 59 & 84 & 43 & 41 & 100 & 105 & 650 & 646 \\
\hline 80th perc. & 141 & 218 & 123 & 82 & 183 & 244 & 1099 & 1006 \\
\hline 90th perc. & 365 & 592 & 307 & 220 & 451 & 592 & 2541 & 1914 \\
\hline Mean & 202 & 379 & 290 & 157 & 184 & 364 & 1577 & 847 \\
\hline SD & 821 & 1508 & 1842 & 698 & 593 & 1374 & 5806 & 1839 \\
\hline Max & 10,114 & 15,743 & 20,826 & 6511 & 6654 & 14,502 & 61,951 & 14,798 \\
\hline \multicolumn{9}{|l|}{ Year $2014(n=112)$} \\
\hline Median & 0 & 0 & 0 & 0 & 0 & 0 & 46 & 0 \\
\hline 70th perc. & 15 & 0 & 13 & 17 & 10 & 47 & 188 & 196 \\
\hline 80th perc. & 33 & 35 & 37 & 38 & 38 & 73 & 303 & 445 \\
\hline 90th perc. & 77 & 142 & 114 & 52 & 148 & 118 & 746 & 917 \\
\hline Mean & 92 & 73 & 64 & 28 & 68 & 95 & 419 & 299 \\
\hline SD & 382 & 370 & 233 & 73 & 270 & 338 & 1504 & 629 \\
\hline Max & 2812 & 3756 & 1638 & 601 & 2609 & 2757 & 14,173 & 3863 \\
\hline
\end{tabular}

The sum of the ergot-in and -inine forms of the respective alkaloids are indicated. Values $<$ LOQ were calculated as zero values (lower bound) $n$ number of samples, perc. percentile, $S D$ standard deviation, max maximum, $L O Q$ limit of quantification 


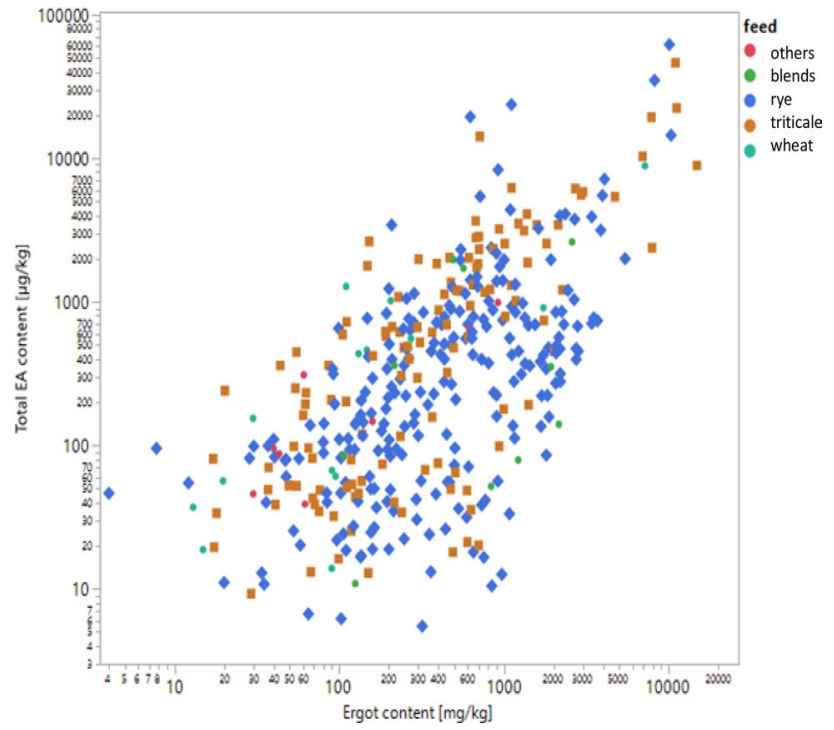

Fig. 1 Logarithmic presentation of the ergot content (x-achses) and the total ergot alkaloids (EA) content (y-achses) in the examined samples ("zero" values are excluded)

\subsection{Toxicity evaluation, derivation of preliminary guidance values for critical diet concentrations and risk evaluation}

\subsubsection{Preamble}

The toxic effects of ergot are mainly due to the EA therein, although other constituents such as ricinoleic acid contribute to the overall effect in animals (Mainka et al. 2003). The individual alkaloids primarily contributing to the total EA content and thereby to the total toxicity of ergot are routinely analyzable. With regard to animal health, risk management based on the chemically analyzable EA content of the daily ration, therefore, offers advantages over that based on ergot content physically determinable in unground cereals only (EFSA 2005, 2012). Figure 2 exemplifies this generic consideration with growing pigs and illustrates it by means of dose-response relationships between ergot content (abscissa values) and performance characteristics (ordinate values) on the one hand, and those between EA content (abscissa values) and the same performance characteristics (ordinate values) on the other hand. The proportion of variation that can be explained by the respective negative linear relationships ( coefficient of determination $=r^{2}$ ) is significantly greater with respect to the EA content of the feed compared to that of ergot (Dänicke and Diers 2013).

It must be added that the reference to the EA content can only be a first approximation to the toxic principle of ergot, since even with the same EA content of feed different effects can be observed in the animal, which are probably caused by different patterns of individual alkaloids (Dänicke and Diers 2012; Mainka et al. 2007). An approach to cope with different alkaloid patterns was proposed by Craig et al. (2015) and included the vascular potency of ergovaline, ergonovine, ergocristine, ergocornine, ergocryptine, and lysergic acid relative to ergotamine. The authors used concentration at the onset of contractile response, half-maximal effective concentration or potency $\left(\mathrm{EC}_{50}\right)$, and maximal response or efficacy $\left(\mathrm{E}_{\mathrm{MAX}}\right)$ of $\mathrm{EA}$ in bovine lateral saphenous veins as endpoints while ergotamine was assigned an ergotamine equivalence level of 1 . Ergovaline, a main EA produced by Epichloë coenophiala

Table 2 Mean and maximum content of EA in different grain types and Pearson correlation coefficients of EA and ergot content grouped by year and grain type for two different sample sets: set 1 includes all samples with ergot contents from min. to max., whereas set 2 represents a subquantity of set 1 comprising only samples with an ergot content $<$ ML of $1000 \mathrm{mg} / \mathrm{kg}$

\begin{tabular}{|c|c|c|c|c|c|c|}
\hline & \multicolumn{2}{|c|}{ Sum of EA content $[\mu \mathrm{g} / \mathrm{kg}]$} & \multicolumn{2}{|c|}{ Set 1} & \multicolumn{2}{|l|}{ Set 2} \\
\hline & Mean & Maximum & $\mathrm{n}$ & $\begin{array}{l}\text { Pearson correlation } \\
\text { coefficient }^{\#}\end{array}$ & $\begin{array}{l}\text { Pearson correlation } \\
\text { coefficient }^{\#}\end{array}$ & $\mathrm{n}$ \\
\hline 2011 & 214 & 1081 & 17 & 0.3889 & 0.2250 & 15 \\
\hline 2012 & 482 & 10,289 & 198 & 0.7626 & 0.6213 & 169 \\
\hline 2013 & 1577 & 61,951 & 273 & 0.7080 & 0.3039 & 204 \\
\hline 2014 & 419 & 14,173 & 112 & 0.2485 & 0.3725 & 91 \\
\hline Wheat & 13 & 8855 & 52 & 0.9746 & 0.6532 & 50 \\
\hline Triticale & 81 & 46,319 & 197 & 0.7560 & 0.4520 & 170 \\
\hline Rye & 112 & 61,951 & 321 & 0.6507 & 0.2867 & 259 \\
\hline Blends & 91 & 216 & 14 & 0.4382 & 0.5329 & 11 \\
\hline Others* & 91 & 989 & 16 & 0.9359 & 0.9359 & 16 \\
\hline All & 86 & 61,951 & 600 & 0.6796 & 0.3485 & 506 \\
\hline
\end{tabular}

$n$ number of samples

*oats, other grains, feed supplements, complete feeding stuff for cattle, pigs, etc

\# calculation by using JMP ${ }^{\circledR} 13$, correlations multivariate 
Table 3 Preliminary guidance values for critical concentrations of total EA (sum of all analyzed individual alkaloids) in the daily ration of livestock ( $\mathrm{mg} / \mathrm{kg}$ diet, $88 \%$ dry matter)

\begin{tabular}{ll}
\hline Animal species/category & $\begin{array}{l}\text { Preliminary guid- } \\
\text { ance value }[\mathrm{mg} / \mathrm{kg}]\end{array}$ \\
\hline Pigs & \\
Rearing piglets, growing fattening pigs & 0.6 \\
Sows & 0.03 \\
Cattle and sheep (all categories) & 0.1 \\
Poultry & \\
Fattening chickens (broilers) & 1.9 \\
Laying hens & 3.7 \\
Fattening pekin ducks & 0.06 \\
\hline
\end{tabular}

The values take into account only an average alkaloid pattern, which is typically expected for ergot on rye in Germany. Variations in the alkaloid patterns as well as the remaining chemical (toxic) components could not be used for the derivation due to a lack of experimental data. Uncertainty factors were applied to account for these incomplete data

infecting tall fescue (Festuca arundinacea), was shown as potent as ergotamine; therefore, an ergotamine equivalence level of 1 was assigned to this EA. All other considered EA reached ergotamine equivalence levels of lower than 1 , ranging from 0.1 to 0.001 . This system assumes the vasoconstriction activities of EA as the main toxic principle but does not consider possible interactions between alkaloids and non-vasoconstriction effects.

Based on the uncertainties regarding variations in EA patterns and the consequences in terms of toxicity, the derived guidance values for the sum of all EA strictly
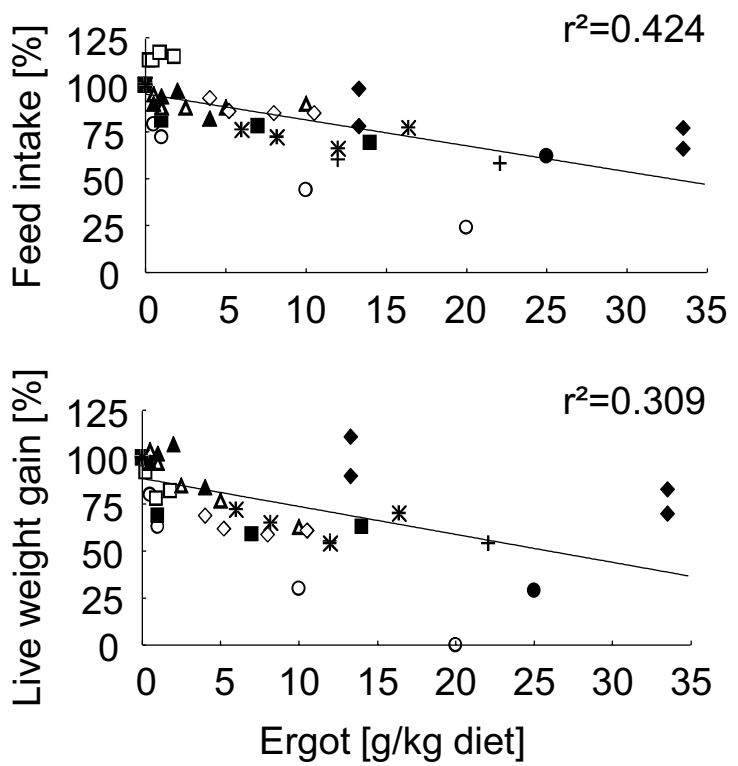

apply only to those EA patterns (variations in ergot of German origin) used in the underlying studies (Fig. 1).

\subsection{Derivation of preliminary guidance values}

All EA concentrations discussed in this section refer to a basic dry matter content of $88 \%$.

The preliminary guidance value (Table 3 ) for pigs of $0.6 \mathrm{mg} \mathrm{EA} / \mathrm{kg}$ feed corresponds to the lowest NOAEL found for pigs of various categories, which was determined from the studies of Mainka et al. (2005a) on fattening pigs for different endpoints (feed intake, body mass gain, clinicalchemical traits, organ weights). This value is significantly lower than the NOAEL of $3.57 \mathrm{mg}$ EA/ $\mathrm{kg}$ diet or $5.6 \mathrm{mg}$ $\mathrm{EA} / \mathrm{kg}$ feed for rearing piglets, which can be derived from the significant changes in feed intake and live weight gain compared to the respective control groups (Mainka et al. 2005b; 2007).

Based on the significant reductions in prolactin concentrations in systemic blood, Kopinski et al. (2007) reported critical concentrations of 0.33 and $1 \mathrm{mg}$ EA/kg feed for primiparous and pluriparous sows, respectively. These values, however, have to be interpreted restrictively as they were derived after exposure to Claviceps africana whose content of total EA is predominantly determined by dihydroergosine that is rarely found in C. purpurea. In view of this significantly different alkaloid pattern, it does not appear justified to apply $C$. africana-derived critical concentrations to $C$. purpurea which predominantly occurs on nonsorghum cereals without taking into account a safety factor. The need to employ a safety factor also arises from the
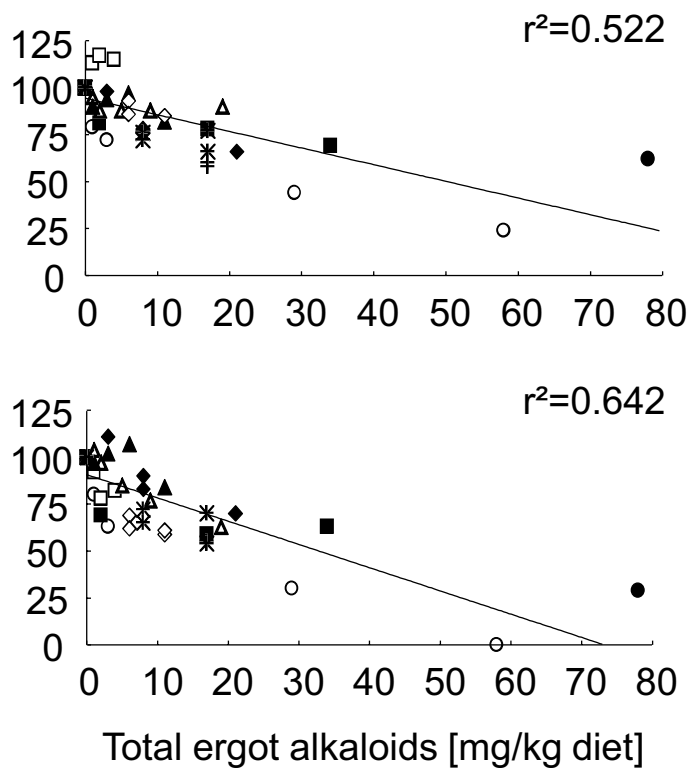

Fig. 2 Literature compilation of dose-response relationships between the ergot content (left) and the total EA content (right) of feed and various performance characteristics of growing pigs (Dänicke and Diers 2013) 


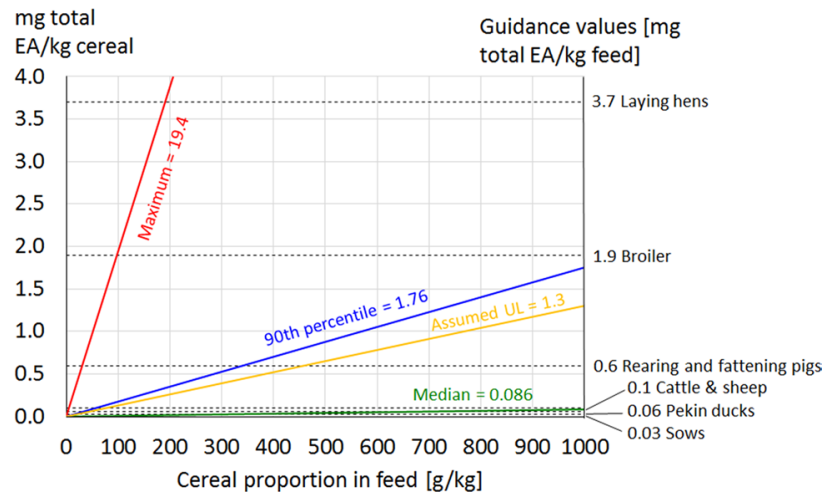

Fig. 3 Risk evaluation for different animal species and categories, based on the preliminary guidance values for critical concentrations of EA in feed: the intersections between the horizontal dotted lines (= preliminary guidance values) with the rising straight lines characterize the critical cereal proportions in feed at EA concentrations in the grain which represent the median, the maximum concentration, the 90th percentile of the monitoring data, and an assumed average concentration of $1300 \mu \mathrm{g} \mathrm{EA} / \mathrm{kg}$ (corresponds to the upper limit, UL, of $\mathrm{mg}$ ergot $/ \mathrm{kg}$ )

fact that dihydroergosine is significantly less toxic than the C. purpurea-originating alkaloids (Kopinski et al. 2007). Conservatively, a preliminary guideline value of $0.03 \mathrm{mg}$ $\mathrm{EA} / \mathrm{kg}$ for sows is derivable when assuming a safety factor (LOAEL-to-NOAEL Uncertainty Factor, UF) (Opresko et al. 1998) of 10, and for the more sensitive primiparous sows a critical dietary concentration of $0.33 \mathrm{mg} \mathrm{EA} / \mathrm{kg}$.

Mares appear to respond also quite sensitively to the presence of EA in endophyte infected tall fescue manifested in a marked reduction in prolactin levels and associated agalactia exhibiting a prolonged gestation length and an increased incidence of Retentio secundinarum (Monroe et al. 1988). However, no data on EA concentrations were reported in that study. Therefore, mares can presently not be considered and require further investigations.

The dose-response studies published for growing cattle of the German Holstein breed do not allow the derivation of either a LOAEL or a NOAEL, since the maximum tested levels for calves ( $0.85 \mathrm{mg} \mathrm{EA} / \mathrm{kg})$ and bulls $(0.37 \mathrm{mg} \mathrm{EA} /$ $\mathrm{kg}$ ) were too low to cause adverse effects (Schumann et al. $2007 a, b)$. In dairy cows of the same breed, rectal temperature, which was not recorded in the studies on growing cattle, was significantly increased up to a concentration higher than $0.44 \mathrm{mg} \mathrm{EA} / \mathrm{kg}$ (Schumann et al. 2008), which can be interpreted as a LOAEL. However, this physiological deviation had no negative impact on a number of endpoints recorded in these studies. Thus, neither milk yield, liver cell damage-indicating enzyme activities in blood serum nor rumen fermentation parameters were influenced by EA exposure (Schumann et al. 2008; 2009). Obviously, the rectal temperature as an expression of the vasoactive effects of some EA represents a sensitive toxicological endpoint in dairy cows. This preliminary LOAEL of $0.44 \mathrm{mg} \mathrm{EA} / \mathrm{kg}$ is close to the level of $0.473 \mathrm{mg} \mathrm{EA} / \mathrm{kg}$ mainly consisting of ergotamine which was found to be associated with clinical cases of tail losses in cattle putatively due to the vasoconstriction activity of EA (Craig et al. 2015; Klotz 2015). Other clinical signs in cattle observed at higher EA levels between 1.5 and $62 \mathrm{mg} \mathrm{EA} / \mathrm{kg}$ included lameness, sloughing of hooves, decreased feed intake, early term abortions and low milk yield (Klotz 2015).

However, since other animal health, physiological and performance characteristics were unaffected in the study by Schumann et al. (2008), a LOAEL-to-NOAEL UF of only 5 is assumed. Therefore, a LOAEL of $0.44 \mathrm{mg} \mathrm{EA} / \mathrm{kg}$ determined in dairy cows results in a preliminary guidance value of $0.1 \mathrm{mg} \mathrm{EA} / \mathrm{kg}$, which is applied conservatively to growing cattle as well.

In sheep (ram lambs), increasing doses of EA from cereals raising up to $2447 \mathrm{mg} / \mathrm{kg}$ resulted in a linear dose-dependent decrease in serum prolactin concentration (Coufal-Majewski et al. 2017). Even the lowest concentration of $0.93 \mathrm{mg} \mathrm{EA} /$ $\mathrm{kg}$ caused a significant decrease in prolactin levels compared to the control group and would consequently represent an estimate for a LOAEL since other recorded endpoints responded nothing at all (nutrient digestibility) or only at higher concentrations (performance). Applying a LOAELto-NOAEL UF of 10 would lead to a preliminary guidance value of $0.09 \mathrm{mg} \mathrm{EA} / \mathrm{kg}$ or rounded up to $0.1 \mathrm{mg} \mathrm{EA} / \mathrm{kg}$, which is similar to that for cattle. Conservatively, this value should apply to all sheep categories.

In the case of poultry, there are dose-response studies on chickens and laying hens which enabled the derivation of both a LOAEL and a NOAEL. According to that, the NOAEL of $1.9 \mathrm{mg} \mathrm{EA} / \mathrm{kg}$ for fattening chickens (broilers) (Dänicke 2017) and $3.7 \mathrm{mg} \mathrm{EA} / \mathrm{kg}$ for laying hens (Dänicke 2016) are taken as the respective preliminary guidance values. In the case of fattening Pekin ducks, the lowest tested dose of $0.6 \mathrm{mg} \mathrm{EA} / \mathrm{kg}$ was already proved effective in terms of performance and animal health as a result of a dose-response study so that it corresponds to the LOAEL (Dänicke 2015). Assuming a LOAEL-to-NOAEL UF of 10 results in a preliminary guidance value of $0.06 \mathrm{mg} \mathrm{EA} / \mathrm{kg}$.

\subsubsection{Risk evaluation}

Although monitoring the occurrence of EA in feedstuffs as discussed above mainly included samples that were suspected for ergot contamination, the descriptive statistical parameters such as median, 90th percentile and maximum concentrations of total EA were used for a first risk evaluation based on the preliminary guidance values. Thus, this approach can be regarded as conservative and should be 
qualified in the future by monitoring data based on sampling plans and not on suspect samples.

In doing so, maximum tolerable cereal proportions in the daily ration can be derived for different animal species and categories. For this purpose, EA contents in feed are to be related to the preliminary guidance values representing the median, the 90th percentile and the maximum concentration from the above discussed EA monitoring, as well as a value of $1300 \mu \mathrm{g} \mathrm{EA} / \mathrm{kg}$ corresponding to the upper limit of $1000 \mathrm{mg}$ ergot/kg on average (SANCO/1525/2006 -rev. 2).

When applying the median concentration, the use of contaminated cereals for sows, Pekin ducks and cattle seems limited. However, under practical feeding conditions, the median appears to be less suitable for a risk evaluation than the concentrations corresponding to the 90th percentile or the maximum EA concentration in the feed, since in individual cases a specific damage situation in livestock will be associated with such (higher) concentrations. Assuming such scenarios, there are, however, limitations for all animal species and categories considered. At concentrations corresponding to the 90th percentile and the assumed concentration of $1300 \mu \mathrm{g} / \mathrm{kg}$, there are limitations for not only sows, fattening Pekin ducks and cattle for grain use, but also for rearing pigs and fattening pigs (46\%).

EFSA-estimations of EA contents in diets for various animal species and categories would suggest that guidance values for sows, fattening Pekin ducks, cattle and sheep would be exceeded irrespective of exposure scenario (i.e. lower and upper bound mean levels), but particularly when rye was included in the diets (EFSA 2017). In contrast, earlier estimations by the EFSA (2012) suggested no exceedance of the preliminary guidance values for any of the farm animal species or categories. Only when rye was included in the scenarios, the guidance value for sows was surpassed.

Based on these apparently contradictory estimations a systematic monitoring of complete feed seems to be advisable in order to evaluate the exposure of the animals more realistically.

\subsubsection{Conclusions for toxicity evaluation}

Individual species or categories of animals are insufficiently protected by the currently applicable upper limit of $1000 \mathrm{mg}$ ergot per kilogram of unground cereals. This is true for different scenarios of presumed EA levels in ergot contaminated cereal grains. Assuming an average EA content of $1.3 \mathrm{mg} / \mathrm{kg}$ in cereals, for sows no more than 2 , for fattening Pekin ducks 4, for cattle and rearing piglets 8 as well as for growing fattening pigs $46 \%$ of the contaminated cereals can be mixed into the ration in order to comply with preliminary guidance values for the critical EA concentrations (Fig. 3). Assuming a median concentration of $0.086 \mathrm{mg} \mathrm{EA} / \mathrm{kg}$ in cereals, as determined in the present study, these acceptable cereal levels for sows and fattening Pekin ducks increase up to 30 and $64 \%$, respectively, while for cattle and rearing piglets as well as for growing fattening pigs there would exist no limitations.

As these preliminary guidance values are based on only a few studies and selected farm animal species and categories further dose-response experiments are required enabling the titration of both LOAEL and NOAEL. Such trials should not only cover hitherto less considered species like horses, pets etc. but also varying EA patterns at comparable total EA contents as a precondition for an improved risk management.

\section{Overall conclusions}

1. The analyzed feed samples showed a significant variability of EA content, even if the ergot content remained the same. Therefore, the calculation of the EA content is not possible based on the weight of ergot counted in the feed.

2. As a consequence, feeding studies have shown that the evaluation of the risk for animal health should be based on the EA content rather than the ergot content.

3. Taking the evaluation of the feeding studies into account, the current regulation restricting the ergot content in feed materials and compound feed containing unground cereals has to be considered insufficient to protect animal health.

4. Based on the current knowledge preliminary guidance values for species-specific critical values for total EA content in the diets could be derived (Table 3 ).

5. Since differences in the effects on animals could be observed even when the EA content within the feed remained the same, further research is needed to verify the preliminary guidance values on the basis of a broader data base and to improve the risk evaluation in view of the significant variability in the species-specific sensitivity.

Funding Open Access funding enabled and organized by Projekt DEAL.

\section{Compliance with ethical standards}

Conflict of interest The authors declare that they have no conflict of interest.

Open Access This article is licensed under a Creative Commons Attribution 4.0 International License, which permits use, sharing, adaptation, distribution and reproduction in any medium or format, as long as you give appropriate credit to the original author(s) and the source, 
provide a link to the Creative Commons licence, and indicate if changes were made. The images or other third party material in this article are included in the article's Creative Commons licence, unless indicated otherwise in a credit line to the material. If material is not included in the article's Creative Commons licence and your intended use is not permitted by statutory regulation or exceeds the permitted use, you will need to obtain permission directly from the copyright holder. To view a copy of this licence, visit http://creativecommons.org/licenses/by/4.0/.

\section{References}

BMEL (Bundesministerium für Ernährung und Landwirtschaft) (2014) Handlungsempfehlungen zur Minimierung von Mutterkorn. https ://www.bmel.de/SharedDocs/Downloads/DE/_Verbraucherschutz/ Lebensmittelsicherheit/HandlungsempfehlungMutterkornalkalo ide.pdf?_blob=publicationFile $\& v=2$. Accessed 20 Aug 2020

BVL (Bundesamt für Verbraucherschutz und Lebensmittelsicherheit) (2010) Amtliche Sammlung von Untersuchungsverfahren nach $\S$ 64 LFGB, Analyseverfahren für die Untersuchung von Futtermitteln; F 0104. https://www.methodensammlung-bvl.de/de/dokum ente/futtermittel/207910! search?pageNum $=1 \&$ state $=\mathrm{H} 4$ sIA AAAAAAAAF2Ry26DMBBFf6XymkXpMrtUSBUbigK7q qrGZkJc_CDjcSUa5d9LlUBxl-fMQ3PtiwDpy07sXDQmE-CUfdIFYidEH98iJL0kLqGgWNIXYtktbu7GHqQWMxddtmvI hE6LgiOvLjOqz1taKhoA-004oqTc2Ax_8dPG_4Ck6e4VogkOd7L9dMnDSHGqmGf16eP2ZCq3sSY2XfRPmJil_Ix3GZ 9krFEVh7By YpnCPSdJulaDDgGiUgkDo9ez9YoCG1pUu58 rzGDP73Od5E83poP4qyeoCgxPvsOXZTDQQ2LK1M0GFyzm 3dnhCWX73-ALdC0QTkAQAA. Accessed 20 Aug 2020

Coufal-Majewski S, Stanford K, Mcallister T, Wang Y, Blakley B, Mckinnon J, Swift ML, Chaves AV (2017) Effects of continuously feeding diets containing cereal ergot alkaloids on nutrient digestibility, alkaloid recovery in feces, and performance traits of ram lambs. Toxins (Basel) 9(12):405

Craig AM, Klotz JL, Duringer JM (2015) Cases of ergotism in livestock and associated ergot alkaloid concentrations in feed. Front Chem 3:1-6

Dänicke S (2015) Ergot alkaloids in feed for pekin ducks: toxic effects, metabolism and carry over into edible tissues. Toxins 7:2006

Dänicke S (2016) Toxic effects, metabolism, and carry-over of ergot alkaloids in laying hens, with a special focus on changes of the alkaloid isomeric ratio in feed caused by hydrothermal treatment. Mycotoxin Res 32:37-52

Dänicke S (2017) Ergot alkaloids in fattening chickens (broilers): Toxic effects and carry over depending on dietary fat proportion and supplementation with non-starch-polysaccharide (NSP) hydrolyzing enzymes. Toxins (Basel) 9(4):118

Dänicke S, Diers S (2012) Effects of ergot alkaloids on liver function of piglets can be detected by the 13C-methacetin breath test irrespective of oral or intramuscular route of tracer administration. Isot Environ Health Stud 48:558-572

Dänicke S, Diers S (2013) Effects of ergot alkoloids in feed on performance and liver function of piglets as evaluate by the 13C-methacetin breath test. Arch Anim Nutr 67:15-36

European Commission (2002) Directive 2002/32/EC of the European Parliament and of the Council of 7 May 2002 on undesirable substances in animal feed. Off J Eur Union L 140/10)
European Commission (2012) Commission recommendation 2012/154/ EU of 15 March 2012 on the monitoring of the presence of ergot alkaloids in feed and food. Off J Eur Union L 77/20

EFSA (European Food Safety Authority) (2005) Opinion of the scientific panel on contaminants in food chain on a request from the commission related to ergot as undesirable substance in animal feed. EFSA J 225:1-27

EFSA (European Food Safety Authority) (2012) Scientific opinion on ergot alkaloids in food and feed. EFSA J 10:2798

EFSA (European Food Safety Authority) (2017) Human and animal dietary exposure to ergot alkaloids. EFSA J 15:4902

Klotz JL (2015) Activities and effects of ergot alkaloids on livestock physiology and production. Toxins 7:2801-2821

Kopinski JS, Blaney BJ, Downing JA, Mcveigh JF, Murray SA (2007) Feeding sorghum ergot (Claviceps africana) to sows before farrowing inhibits milk production. Aust Vet J 85:169-176

Mainka S, Dänicke S, Coenen M (2003) On the influence of ergot contaminated feed on health and performance of pigs and chickens. Übers Tierernährg 31:121-168

Mainka S, Dänicke S, Böhme H, Ueberschär K-H, Polten S, Hüther L (2005a) The influence of ergot-contaminated feed on growth and slaughtering performance, nutrient digestibility and carry over of ergot alkaloids in growing-finishing pigs. Arch Anim Nutr 59:377-395

Mainka S, Dänicke S, Böhme H, Wolff J, Matthes S, Flachowsky G (2005b) Comparative studies on the effect of ergot contaminated feed on performance and health of piglets and chickens. Arch Anim Nutr 59:81-98

Mainka S, Dänicke S, Böhme H, Ueberschär K-H, Liebert F (2007) On the composition of ergot and the effects of feeding two different ergot sources on piglets. Anim Feed Sci Technol 139:52-68

Monroe JL, Cross DL, Hudson LW, Hendricks DM, Kennedy SW, Bridges WC (1988) Effect of selenium and endophyte-contaminated fescue on performance and reproduction in mares. J Equine Vet Sci 8:148-153

Opresko DM, Young RA, Faust RA, Talmage SS, Watson AP, Ross RH, Davidson KA, King J (1998) Chemical warfare agents: estimating oral reference doses. Rev Environ Contam Toxicol 156:1-183

Schumann B, Dänicke S, Hübner S, Ueberschär K-H, Meyer U (2007) Effects of different levels of ergot in concentrate on the health and performance of male calves. Mycotoxin Res 23:43-55

Schumann B, Dänicke S, Meyer U, Ueberschär K-H, Breves G (2007b) Effects of different levels of ergot in concentrates on the growing and slaughtering performance of bulls and on carry-over into edible tissue. Arch Anim Nutr 61:357-370

Schumann B, Lebzien P, Ueberschär K-H, Spilke J, Höltershinken M, Dänicke S (2008) Effects of the level of feed intake and ergot contamination on ruminal fermentation and on physiological parameters in cows. Mycotoxin Res 24:57-72

Schumann B, Lebzien P, Ueberschär K-H, Dänicke S (2009) Effects of the level of feed intake and ergot contaminated concentrate on ergot alkaloid metabolism and carry over into milk. Mol Nutr Food Res 53:931-938

Sciurba E, Unbehend G, Füllgrabe N, Begemann J, Hüsken A (2017) Die Qualität der deutschen Roggenernte 2017. Mühle und Mischfutter 21:677-686

Publisher's Note Springer Nature remains neutral with regard to jurisdictional claims in published maps and institutional affiliations. 